\title{
Greening Kenya's Special Economic Zones and Industrial Parks: Achieving their Competitiveness in the face of Resource Scarcity and a Changing Climate Regime
}

${ }^{1}$ Kelvin Khisa, ${ }^{2}$ Arthur Onyuka

\author{
${ }^{1}$ Environment Division of the Kenya Industrial Research and Development Institute \\ (KIRDI), Nairobi, Kenya \\ 2 Leather Division of the Kenya Industrial Research and Development Institute (KIRDI), \\ Nairobi, Kenya
}

\begin{abstract}
The culture of industrialization through special economic zones (SEZs) and industrial parks (IPs) is gathering momentum in Kenya. Increasingly, the Kenyan private sector is recognizing that SEZs/IPs do provide an enabling environment for manufacturing comprising of energy, water, telecommunications, transport, and waste management infrastructure that is non-existent in other manufacturing locations across the country. Because SEZs/ IPs concentrate industries in delimited zones, their strict adherence to the ideals of resource use efficiency and eco-innovation as well as waste and by-product exchange through industrial symbiosis (IS) will enable them increase their productivity and lower their carbon footprints while remaining competitive. Unfortunately, the current master plans governing the planning, design, construction, and operationalization of the country's SEZs/IPs are based on the wasteful linear economic development model of extracting raw materials, converting them into consumable products and discarding the resultant wastes into the landfill/ dumpsite. This traditional linear economic development model is characterized with linear flows of matter, where raw material inputs are mined, value added into desired products, made use of, and discarded with a trail of waste at every stage of the supply chain. Such an approach to economic development can only be sustainable in a situation where the country is endowed with endless resources for its increasing demand and that land is always available for waste disposal. This is certainly not the case for Kenya. As a result, there is emerging international consensus that over-reliance on wasteful linear economic development models is no longer sustainable. A much more promising economic development model is one that seeks to promote a circular economy that is powered by enhanced resource use efficiency, the adoption of the $3 R$ philosophy of reducing, reusing, and recycling wastes, before engaging industrial symbiosis to deal with the inevitable residual waste. This paper highlights the environmental and socio-economic benefits of the spontaneous evolution of industrial symbiosis at the Athi River SEZ in four clusters. The results reveal a spontaneously emerging cluster network within the economic zone that is largely driven by the prevailing forces of supply and demand; an existing intercompany material flow system that is being hampered by a weak waste recovery and recycling infrastructure; a limited application of the principles of industrial ecology in mitigating the environmental challenges of the economic zone; and a weak governance structure that is incapable of enabling the entire economic zone to assume low-carbon, resource efficient and climate resilient operational status.
\end{abstract}

Keywords: Industrial symbiosis, Linear, Circular, Spontaneous, Industrial park 


\section{Introduction}

The culture of industrialization through special economic zones (SEZs) and industrial parks (IPs) is gathering momentum in Kenya. This is well articulated in the country's current Medium Term Plan (MTP II) for 2013-2017 and strongly re-emphasized in the upcoming MTP III (2018 - 2022). Increasingly, the Kenyan private sector is recognizing that SEZs/ IPs do provide an enabling environment for manufacturing through the provision of energy, water, telecommunications, transport, and waste management infrastructure that is non-existent in other manufacturing locations across the country. Because SEZs/ IPs concentrate industries in delimited zones, their strict adherence to the ideals of resource use efficiency and eco-innovation as well as waste and by-product exchange through industrial symbiosis (IS) will enable them increase their productivity, lower their carbon footprints and remain competitive.

Unfortunately, the master plans governing the planning, design, construction, and operationalization of the country's SEZs/IPs are based on the wasteful linear economic development model of extracting raw materials, converting them into consumable products and discarding the resultant wastes into the landfill/ dumpsite. This traditional linear economic development model is characterized with linear flows of matter, where raw material inputs are mined, value added into desired products, made use of, and discarded with a trail of waste at every stage of the supply chain. Such an approach to economic development can only be sustainable in a situation where the country is endowed with endless resources for its increasing demand and that land is always available for waste disposal. This is certainly not the case for Kenya.

As a result, there is emerging international consensus that over-reliance on wasteful linear economic development models is no longer sustainable. A much more promising economic development model is one that seeks to promote a circular economy that is powered by enhanced resource use efficiency, the adoption of the $3 R$ philosophy of reducing, reusing, and recycling wastes, before engaging industrial symbiosis to deal with the inevitable residual waste. Nowhere can this be done with ease than in a special economic zone (SEZ) where industries are located in close proximity with shared infrastructure. Moving towards the adoption of a zero waste society not only makes environmental sense but is increasingly becoming an important factor of productivity and increased competitiveness. Doing this will help divert va luable waste streams from the landfill and also aid in reducing pressure on the use of virgin raw materials. Given the great danger posed by a changing climate regime, promoting resource use efficiency, diverting wastes from the landfill, and re-circulating materials again and again in closed loop manufacturing value addition cycles will definitely reduce the amount of climate damaging greenhouse gas (GHG) emissions.

This paper highlights the environmental and socio-economic benefits of the spontaneous evolution of industrial symbiosis at the Athi River SEZ in four clusters. The results reveal a spontaneously emerging cluster network within the economic zone that is largely driven by the prevailing forces of supply and demand; an existing intercompany mate rial flow system that is being hampered by a weak waste recovery and recycling infrastructure; a limited application of the principles of industrial ecology in mitigating the environmental challenges of the economic zone; and a weak governance structure that is incapable of enabling the economic zone to assume low-carbon, resource efficient and climate resilient operational status. For the economic zone to fully adopt low-carbon and resource efficient status, its tenant companies must unanimously shift their production lines from linear to closed loop systems where wastes from one production line become inputs for the other. Doing this will reduce pressure on the use of virgin materials and also lower the carbon footprint of the economic zone by diverting vast amounts of waste from the landfill. 


\subsection{Problem Statement}

Kenya's current industrial development model is largely linear. It is based on the wasteful linear development economic model of extracting raw materials, converting them into consumable products and discarding the resultant wastes into the landfill. This traditional linear development model is characterized by linear flows of matter, where raw material inputs are mined, value added into desired products, made use of, and discarded with a trail of waste at every stage of the supply chain (Bermejo, 2014). Such an approach to economic development can only be sustainable in a situation where the country is endowed with endless resources for its increasing demand. This is certainly not the case. As a result of this realization, there is a strong international consensus that over-reliance on wasteful linear economic development models is no longer sustainable. A much more promising economic development model is one that seeks to promote a circular economy that is powered by enhanced resource use efficiency, the adoption of the $3 R$ philosophy of reducing, reusing, and recycling wastes, before engaging industrial symbiosis to deal with the inevitable residual waste. Doing this will help divert waste streams from the landfill and also reduce pressure on the use of virgin raw materials. Given the great danger posed by a changing climate regime, promoting resource use efficiency, diverting wastes from the landfill, and re-circulating materials aga in and again in closed loop manufacturing value addition cycles will definitely reduce the a mount of climate damaging greenhouse gasses (GHG). The climate change and environmental shortcomings associated with un-regulated economic zones can easily over ride their proven socio-economic advantages if environmentally friendly interventions such as industrial symbiosis are not incorporated.

This research project sought to assess what needs to be done at the Athi River SEZ so that the zone can be enabled to abandon the wasteful and environmentally polluting linear economic development model and instead embrace the much more promising circular economy. Switching to a zero waste circular economy as it has sustainably happened in natural ecosystems not only advances prudent and sustainable use of scarce resources but also opens a window for industrial spin-offs that generate green jobs. Successful adoption of a circular economy using industrial symbiosis at the Athi River SEZ will require enhanced institutional capacity in green growth promotion, demonstrated awareness that investing in industrial symbiosis makes good economic and environmental sense, and a functional infrastructure for waste recovery and recycling that are all being addressed by this research project. In an industrial ecosystem, production is organized in such a synergistic manner that mimics natural systems so that waste from one company becomes a resource for another company (UNEP, 2011; UNIDO, 2015).

Kenya Vision 2030 currently guides the country's development agenda (GOK, 2013). The vision recognizes industrialization as one of the key pillars of economic growth and wealth creation (GOK, 2013; 2015). As a result, there has been a marked proliferation of un-regulated special economic zones (SEZs) across the country. Kenya currently boasts of 57-gazetted public and private SEZs and this number is rapidly increasing (Export Processing Zones Program Annual Performance Report, 2013). Plans are underway to establish a total of 10 industrial parks/ special economic zones (SEZs) along the country's major infrastructure corridors ${ }^{1}$. SEZs do concentrate industrial plants in a designated geographical area with increased levels of pollution in form of climate changing emissions and solid wastes (World Bank, 2014). There is need therefore for cluster wise planning and zonation of the economic zone, a practice that is yet to be embraced by the Zone Authority. This has resulted in inefficient use of raw materials, energy and water with significant generation of wastes and emissions. Stockpiles of solid wastes are visible within the economic zone.

The initial zone master plan was not designed with the ideals of sustainability in mind. This means that there was no deliberate attempt to zone and cluster together industrial plants that

${ }^{1}$ GOK, 2015. Kenya's Industrial Transformation Program, Ministry of Industry, Investment and Trade. 
could exchange wastes and by-products. Therefore, zone resident companies are not in a position of fully benefiting from economic and environmental savings that could result from embracing resource use efficiency at company level and industrial symbiosis comprising of closed material, energy and/or water cycles within the clusters of co-located industries (UNIDO, 2015). Without this deliberate move, the Athi River SEZ will not be in a position of attracting green foreign direct investments (FDIs) (GIZ, 2015a). Absence of a clear industrial policy that prioritizes Industrial Ecology is to blame for the country's over reliance on this wasteful linear development economic model. This study targets policy makers, industrialists, managers of SEZs/ IPs, consultants, and researchers with the message that investing in a circular economy that seeks to divert wastes from the landfill makes good business and environmental sense.

\subsection{Aim of the Study}

The general objective of this study was to assess the efficacy of Industrial Ecology as an environmental governance model for transforming the wasteful Athi River SEZ's linear development model into a green and sustainable closed loop supply chain. This will entail working innovatively to ensure that materials destined to the landfill are diverted to economic use.

\section{Literature Review}

\subsection{Weaknesses in the SEZ Legal and Policy Framework}

The Kenyan Government has in place a draft SEZ policy and the SEZ Act that both do not incorporate the desired sustainability elements of industrial ecology and green growth. Both the draft SEZ policy and Act do not prioritize the need to develop low carbon, green and resource efficient SEZs. This is against the global trend that is being advocated for by UNEP and the World Bank Group that see to promote environmentally friendly eco-industrial economic zones that are powered by resource use efficiency, cleaner production and industrial symbiosis (UNEP, 2011; World Bank, 2014). As has been demonstrated in China and South Korea, it makes economic and environmental to embrace eco-industrial parks (EIPs) that are designed from the beginning to be environmentally friendly.

Although Kenya's industrialization policy mentions cleaner production as an approach to waste minimization at source, it is silent on how to deal with the inevitable residual waste that is the target of industrial ecology. As is expected, the Green Growth agenda that came into being in 2012 (Rio +20 ) as an innovative approach to achieving sustainable development goals (SDGs) is not directly mentioned in Government policy documents that were published earlier than 2012. This category includes the Kenyan Constitution, industria lization policy, and Kenya Vision 2030. Interestingly, due to limited stakeholder consultations, even the Government publications that were published after 2012 such as the amended EMCA, 2015, the SEZ Act of 2015, and the draft SEZ regulations still have no mention of the socio-economic benefits of the prioritized green growth agenda.

The policy framework for green economy in Kenya is spelled out in the constitution of Kenya 2010, Kenya Vision 2030, Green Economy Strategy and Implementation Plan (GESIP), National Climate Change Response Strategy (NCCRS)2 , National Climate Change Action Plan (NCCAP) ${ }^{3}$, the draft Environmental Policy, the draft Kenyan Climate Change Policy of 2014 and the Climate Change Act, Number 11 of 2016. It's hoped that Kenya's resource constraints and environmental pressures will accelerate its transformation from a linear extraction-use-throw-away model of

\footnotetext{
${ }^{2}$ GOK, 2010. National Climate Change Response Strategy (NCCRS), Ministry of Environment, Water, and Natural Resources

3 GOK, 2013. National Climate Change Action Plan (NCCAP) for 2013-2017, Ministry of Environment, Water, and Natural Resources
} 
economic growth into a closed loop supply chain as has been ably demonstrated in Asia and Europe (EC Decision, 2014). These noble intentions are already spelled out in the country's National Climate Change Action Plan (NCCAP) and its Green Economy Strategy and implementation Plan (GESIP), but not in the SEZ Act, draft SEZ policy and SEZ regulations. Despite a significant increase in waste materials recovery in Kenya, the end of life cycle for most of the country's products is unfortunately still the land fill. The Government has committed to be allocating $2 \%$ of its GDP to the National Research Fund (NRF) established by the Science Technology and Innovation (STI) Act of 2013, however, there has been little progress towards the fulfilment of this goal.

\subsection{Planning of the Athi River SEZ}

The Athi River SEZ was not planned for waste and by-product exchange among companies. Its master plan did not incorporate elements of sustainability. In other words, there was no deliberate effort of zoning the park in such a way that those companies that can exchange wastes and by-products are located in close proximity. However, due to the prevailing market forces, there is emerging exchange of wastes and by-products among companies, a development that should be investigated to guide future zone planning and management. In order for the zone to be classified as low carbon and green, it should deliberately start embracing resource use efficiency through cleaner production and waste and by-product exchange through industrial symbiosis. This sequential approach to materials management is not currently being fully embraced by the tenant companies of the Athi River zone.

The Kenyan Athi River SEZ was planned, designed, built and run with little concern for its impact on the environment and that explains why there has been a marked accumulation of wastes and by-products within its zone boundaries over time. The economic zone operates a wide range of industrial establishments that leads to a cumulative effect of the environmental impacts of individual companies within the zone with each company attempting to fix its challenges single handedly. This should not be the case. The proximity of companies within the economic zone should be exploited economically by exploring ways and means of enabling these companies to exchange wastes and by-products through industrial symbiosis. By networking and working together, the community of businesses within the economic zone will achieve a collective benefit that will be greater than the sum of individual benefits each company would realize by only optimizing and making efficient its individual performance (Lowe, 1997 \& 2001).

Kenya Vision 2030 currently guides the country's development agenda (GOK, 2013). The vision recognizes industrialization as one of the key pillars of economic growth and wealth creation (GOK, 2013; 2015). As a result, there has been a marked proliferation of un-regulated special economic zones (SEZs) across the country. Kenya currently boasts of 57-gazetted public and private SEZs and this number is rapidly increasing (Export Processing Zones Program Annual Performance Report, 2013). Plans are underway to establish a total of 10 industrial parks/ special economic zones (SEZs) along the country's major infrastructure corridors. SEZs do concentrate industrial plants in a designated geographical area with increased levels of pollution in form of climate changing emissions and solid wastes (World Bank, 2014). There is need for cluster wise planning and zonation of the economic zone, a practice that is yet to be embraced by the Zone Authority. Promising smart economies of the future will be those that are continuously striving to minimize the production of waste and reusing wastes as resources in other production lines (EC, 2014). In order to achieve this, the country's SEZs should seek to organize and sequence their industrial production lines in a manner that mimics the circular flow of matter in natural ecosystems so that waste from one production line becomes feed stock for another production line (Wolf et al. 2012).

The initial zone master plan was not designed with the ideals of sustainability in mind. This means that there was no deliberate attempt to zone and cluster together industrial plants that 
could exchange wastes and by-products. Therefore zone resident companies are not in a position of fully benefiting from economic and environmental savings that could result from embracing resource use efficiency at company level and industrial symbiosis comp rising of closed material, energy and/or water cycles within the clusters of co-located industries (UNIDO, 2015). Without this deliberate move, the Athi River SEZ will not be in a position of attracting green foreign direct investments (FDIs) (GIZ, 2015a). Absence of a clear industrial policy that prioritizes Industrial Ecology is to blame for the country's over reliance on this wasteful linear development economic model.

It will therefore be the duty of the Zone Authority to aggressively promote RECP, the $3 R$, and IS within the zone's tenant companies. Investing in RECP has an assured pay back for the tenant companies. Good knowledge of material flows within the production lines is a mandatory requirement for process optimization and industrial symbiosis. The Zone Authority should accurately map out material and energy flows of all companies operating within the zone. Data accruing from this mapping exercise should be entered into a database managed by the Zone Authority through an established information-clearing house. When wastes and by-products are produced within the economic zone, this information should be relayed to a zone wide information platform that should ideally connect all the tenant companies of the zone. With the help of a waste exchange clearing house, it can be possible to match those who generate wastes with those who need those wastes as feed stock raw material input. This matching of the "haves" and "wants" will facilitate negotiated payments for wastes and by-products that could otherwise have been landfilled. A database of generated wastes and by-products will help develop synergies for waste and by-product exchange through industrial symbiosis opportunity workshops. UNIDO states that there are three elements that affect the stable operation of an industrial symbiosis system: (i) communal facilities that support the development of enterprises within the economic zone, such as an information centre, a technological centre, an environmental centre, good road network, a solid waste disposal and recovery site and an energy centre; (ii) relational networks of industrial symbiosis; and (iii) a supportive service which contains the factors that will affect and regulate enterprises within parks in terms of policy, the regulatory regime, park administrators, laws and financing priorities (UNIDO, 2016).

\subsection{Green Economy}

The definitions of Green Economy by four international organizations OECD, UNDP, UNEP and the World Bank are broadly characterized by three objectives: improving resource-use efficiency (a green economy is one that is efficient in its use of energy, water and other material inputs); ensures ecosystem resilience (protects the natural environment, its ecosystems' structures and flows of ecosystem services); and enhances social equity (as it promotes human well-being and fair burden sharing across societies) (NCCAP, 2013; EEA, 2014; GOK, 2015). The concept of Green Economy does not replace that of sustainable development, but should instead be understood as an innovative way of achieving sustainable development (UNEP, 2011). Lowcarbon green growth is a development pathway that decouples economic growth from carbon emissions, pollution and resource use, and promotes development through the creation of new and environmentally friendly products, industries and business models that seek to improve people's quality of life (ADB, 2012; NCCAP, 2013). The United Nations Industrial Development Organization (UNIDO) defines green industry as: "the potential for industries to decouple economic growth and revenues from excessive and increased resource use and pollution (UNIDO, 2011; UNEP 2011). Green industries will be creative and innovative, constantly developing new ways of improving their economic, environmental and social performance (UNIDO, 2011; UNIDO 2015).

\subsection{Solid Waste Management}

The Athi River SEZ does not have a controlled landfill. There is therefore no incentive for tenant companies to seek innovative ways of diverting wastes from the landfill. As a result, there has 
been a marked accumulation of solid wastes in the zone over the years. This can rapidly change if the zone's waste streams can be integrated back into the value addition cycle. The Athi River SEZ has the requisite threshold number of companies to permit cooperative and collaborative approaches to synergies such as waste and by-product exchange. It should be the cardinal duty of the Zone Authority to encourage this. Lack of this intervention means that materials within the economic zone are continuously flowing from the economy into the environment with disastrous impacts. In order for the economic zone to fully embrace the ideals of sustainability, it has to drift away from over reliance on end-of-pipe approaches and instead embrace pollution prevention at source. The end-of-pipe is a reactive approach that creates a problem and then seeks a solution to it. There is urgent need for a more proactive approach that seeks to innovatively avoid the problem of waste generation in the first instance. The tenant companies of the economic zone are at different levels of environmental stewardship. There are a few front runners that are already embracing IS while a great majority of the zone enterprises are yet to embrace IS, leave alone resource use efficiency and cleaner production. Ideally, the economic zone enterprises should be actively engaged in on-site activities that seek to minimize waste generation at source through avoided leakages, spillages and over flows. These waste streams are the pollutants that lower the quality of the surrounding environment. All decisions regarding waste management within the SEZ should be guided by the waste management hierarchy that prioritizes waste avoidance; waste reduction, reuse, recycling, and recovery in order of preference before waste treatment for final disposal as the least preferred option (UNEP, 2011).

\subsection{Introduction of Industrial Symbiosis (IS) into the Operations of the SEZ/IP}

Introduction of industrial symbiosis (IS) at the Athi River SEZ should follow a step wise approach. The initial step should be an exploration of potential networks, to be followed with a feasibility study before final commercialization of the IS $w$ ith the active participation of the private sector (UNIDO, 2016). Potential IS networks should be identified using a bottom up approach. This will entail company in-put/ output data collection for purposes of exploring the existence of new synergy networks. This production data from companies will be reviewed with the sole aim of determining possible waste and by-product exchanges. Tenant companies with potential for waste and by-product exchange will be encouraged by the Zone Authority to participate in the IS network through waste exchange opportunity network seminars and business meetings. For IS to become a cultural practice within the economic zone, there is need for continuous collection of on-site information from zone tenant companies through various forums so that synergy building becomes a continuous exercise that is constantly being refined and improved upon.

The Zone Authority with the help of the Government should then proceed and fund the feasibility studies of the most promising IS synergy networks. Best feasibility results will be derived from team effort with contributions from multi-disciplinary teams. Promising IS proposals should then be developed further into bankable business models with stakeholder input. These proposals should be piloted first within the economic zone so as to be able to establish the best approaches of full scale roll out. The piloting exercise should be strictly monitored so that meaningful feedback is derived to inform future implementation road map. Ideally, the business model should be co-authored with stakeholders as a way of trying to cement their buy-in. Commercialization of the technically and financially feasible business models will have to overcome a wide range of barriers that will include financial, technical and attitudinal. There is need for detailed negotiations that seek to protect the interests of all players, those who generate wastes and those who receive the wastes for use. In fact trust is the foundation of any successful synergy building network. The financial barrier will be overcome by seeking to tap into the emerging green funds at national, bilateral and international levels. Technical barriers will largely be attributed to lack of cleaner and environmentally sound technologies that can be transferred into the country if there is an enabling technology transfer infrastructure and policy that assures value for the investments. Attitudinal barriers will be overcome through training 
and retraining, aw areness raising and organization of study tours to places where IS has worked successfully to demonstrate its environmental and economic benefits.

Firms that will enter this IS network should know that they can compete and cooperate at the same time within the expansive network. There must be a constant flow of waste and byproducts in a reliable manner. This underscores the need for up to date waste recovery and recycling infrastructure. When these waste materials are produced constantly and reliably, the transaction costs will generally come down. It will be important for this synergy seeking approach to build on those networks that have developed org anically or spontaneously on their own due to the prevailing forces of supply and demand. This underscores the fact that for IS to succeed, it must make good business sense and should also be used to create additional efficiencies in terms of lowering the operational cost of doing business. A successful IS network entails a multi connected waste recovery system; a robust training program on waste and byproduct exchange as well as the related synergy building; an infrastructure for waste and byproduct recovery and re use; a system for managing the network and its players; a community liaison and outreach office for managing joint projects with the surrounding community; and a vibrant triple helix collaboration for eco-innovation (World Bank, 2014). The main aim is to create a system of recovering and trading by-products and wastes among zone companies. The noble intention is to divert wastes from the landfill, lower production costs, generate extra revenue from the waste streams, create more decent green jobs, reduce pollution levels, lower disposal costs, and reduce pressure on the use of virgin raw materials (Kechichian \& Jeong, 2016).

This in essence seeks to connect individual operational firms into industrial ecosystems by closing loops through waste and by-product reuse and recycling; maximizing efficiency of materials and energy use; minimizing waste generation at source; and defining all wastes as potential products and seeking markets for them (UNIDO, 2016). It is important to determine which waste streams are already being re-used and recycled on-site and which ones need to be further recovered and diverted from the landfill. The resources that no company is currently using within the economic zone should be identified and appropriate technologies and business models developed to put these resources back to economic use through manufacturing value addition. This will extend the value of the recovered wastes along the production supply chain. There is need for proper planning and analysis if the art of waste and by-product exchange netw orks has to be expanded within the economic zone. According to UNIDO, this should entail characterizing energy, water, and material flows so as to highlight and map out existing and potential exchanges of wastes and by-products; provision of training sessions, tools, and support for the project development processes, data gathering and analysis; gathering further data on resource flows of companies that have committed to the waste and by-product exchange; identifying companies which could process selected materials, providing collection services for specific by-products, or otherwise support the operation of the waste and by-product exchange; identifying for fixing potential barriers in the regulatory frameworks, business practices, and environmental management; and developing a strategic plan for the expansion from simple waste and by-product exchange framework into a full scale eco-industrial network operation (UNIDO, 2016).

The four clusters at the Athi River SEZ have just self-organized as a result of the prevailing market forces of supply and demand. A comprehensive materials flow investigative study is required for the economic zone so that an up to date inventory of wastes and materials is developed. It will also be important to establish waste and by-product exchanges that are spontaneously on-going and those that are currently being discarded into the economic zone but could be otherwise be exchanged and the burden this business as usual practice is having on common infrastructure in form of landfills and centralized effluent treatment plants. The goal should be to help establish innovative new businesses that turn waste and by-product streams 
into feedstocks inputs for other companies. Sustainable waste and by-product exchange should only come after the participating companies have already adopted other environmental management strategies like waste reduction at source, pollution prevention and energy efficiency. It is critically important to assure the synergy participating companies that their trade secrets will not be revealed to third parties. This underscores the need to code the data as a way of preventing unauthorized disclosures.

On-site investigations revealed that at times, there is need for pre-processing of discarded wastes before they are made ready for use by other production lines. The off cuts from plastic tarpaulins manufacture will need to be palletized before being used for plastic water tanks and chairs. This initiative can best be promoted through incubation. Adoption of an incubation framework to fill this gap within the economic zone will enable it not only create more green jobs but also fulfill the wider goal of embracing a closed loop system, that relies on optimized reuse and recycling of wastes and by-products. Once company managers are made aware of the opportunities to cut costs and possibly gain new income through exchange of by-products, they may start negotiating with potential trading partners without need for any enco uragement (UNIDO, 2016). However, lessons learnt from Europe and Asia justify the need for waste exchange opportunity seminars, a privately owned by-product exchange website, and newsletters may be required to open up a more active network of interactive exchanges. There is also need to construct within the economic zone infrastructure in form of conveyor systems and bulk storage facilities to facilitate a smooth exchange.

The developed world has developed software to help facilitate waste and by-product exchange synergies. By matching residual by-products from zone businesses with a generic database, the software can be used to determine potential synergies. This software is yet to be tested at the Athi River SEZ. The ultimate goal is to close the energy and material flow cycles, engage multi stage energy cascading and waste minimization at source, enable waste and by-product exchange through industrial symbiosis for improved productivity, resource use efficiency and competitiveness. At the Athi River SEZ, most tenant companies operate as silos with no formalized communication among them. The economic zone also lacks a platform through which economic zone tenant companies can meet and deliberate on issues of mutual interest such as resource use efficiency, cleaner production and waste and by-products exchange through industrial symbiosis. Kenya's efforts of promoting green growth is at its infancy. As such, there is no policy that currently prioritizes the promotion of industrial symbiosis in the country. For policy makers, industrial symbiosis presents an opportunity to value add on waste streams for improved profitability while at the same time expanding the waste and by-product exchange networks beyond the boundaries of the firm to incorporate external clusters (OECD, 2010).

\section{Research Methodology}

The Athi River SEZ is the oldest and biggest in Kenya having been established on 23 November 1990 by the EPZ Act Cap 517 of the Laws of Kenya. It is the most advanced in terms of road, air, rail and telecommunications infrastructure. It is a public SEZ that commands over $50 \%$ of the EPZ business in the country. The zone that has a perimeter fence possesses a diverse range of industrial establishments with requisite information essential for the realization of my intended study objectives. The Athi River SEZ covers a total gazette land area of $634 \mathrm{ha}$ (Athi River LR No. 18474), out of which $182 \mathrm{ha}(30 \%)$ has already been developed with an additional 454ha (70\%) equivalent to 235 plots of approximate area of 2 ha each awaiting to be developed in the future (EPZ Program Annual Performance Report, 2013). There is therefore enough room for the restructuring and transformation of the zone into an eco-industrial park (EIP). These findings will not only be applicable to the Athi River SEZ but also to all others around the country. This research was undertaken at the Athi River SEZ with a view to establishing what needs to be done so as to transform the zone into a low-carbon and resource efficient industrial 
production system as a way of improving its environmental stewardship. A mixed methods approach was used. The following sequential steps were used to address the four study research questions:

(i) Determination of the evolving clusters of the Athi River special economic zone (SEZ); and

(ii) Scientific analysis of the material flow patterns and how they lead to symbiotic relationships within the identified clusters;

In order to assure validity and credibility, different sources of information were use dincluding interviews, direct observations, at the sites, websites, annual performance reports, statistical abstracts, economic surveys, etc.

The approach entailed the collection of both qua litative and quantitative data sets. Primary data was obtained through questionnaire interviews, zone and process inspections, analysis of utility bills and company records. Secondary data was derived from statistical abstracts, official government industrial survey reports, sessional papers, private sector development strategies (PSDSs), Kenya Vision 2030 blueprint, development plans, zone master plans, operational process manuals, Acts of Parliament, and environmental audit/ impact assessment reports. The focus of this research was to establish the quantities of solid and liquid wastes generated by zone companies and how much of this is exchanged through industrial symbiosis and diverted from the landfill. The approach involved the use of key informant interviews and check lists. During the planning phase of the research, background information about the zone was collected, research objectives and general goal of the research explained to the zone management and modalities of engaging zone companies agreed upon. Background information about the site was obtained from the zone's environmental policy, financial policies relating to the environment, relevant rules and regulations governing the zone, and annual environmental audit reports. Additional zone information specifics included the general zone lay out, site history, land area, on-going manufacturing activities, shared waste management infrastructure, organizational structure as well as its internal environmental policies, procedures and guidelines.

A comprehensive questionnaire covering all aspects of resource use optimization, cleaner production, and industrial symbiosis and targeting a wide range of stakeholders was developed. A zone visit during normal operation hours was arranged with an intention of meeting with the officer in charge of the zone to explain and justify the purpose of the study, assess the extent to which the gathered baseline information was accurate and up to date, make a follow up on the list of preliminary best practice waste management practices, identify and request for additional zone information and arrange for visits to selected zone enterprises. The feedback from this initial site visit was used to finalize the research questionnaire, designed to contain an evaluation criteria for purposes of assessing compliance with relevant legislative and regulatory standards, conformance to internal environmental policies, procedures and guidelines, status of current environmental stewardship, and staff awareness of the economic zone's intemal environmental policies, procedures, techniques and guidelines. The questions also sought to establish whether the companies received by-products or waste products from other companies that are then used as inputs for their production processes or whether their by-products and wastes were used by other companies.

Field work sought to establish how the tenant companies of the zone managed their wastes as regards the existence of waste generation data bases, their interpretation of the threats to health and the environment posed by waste accumulation within the economic zone, whether the economic zone had functional waste management policies, by-laws and rules, establish already attempted strategies within the economic zone for reducing, reusing, recovering and recycling wastes, whether the economic zone already derives energy from waste, presence of adequate waste recovery infrastructure, waste accounting systems and mechanisms, level of 
tenant company compliance to set waste management policies, by-laws and rules as well as general adequate of the infrastructure for waste management within the economic zone. The key research issues relating to water, soil, and air pollution and management within the economic zone included the existence of zone based policies, by-laws, rules, and standards for the control of zone water, soil, and air pollution, adherence to a set water, soil, and air quality criteria, roof top and storm water rain harvesting, recovery of sludge from the effluent stream, existence of programs/ strategies for reducing water usage and pollution and adequacy of infrastructure for managing and controlling water pollution. Staff interviews were undertaken with selected tenant companies of the zone to obta in information on current and past operational practices, deviations from statutory and zone requirements, and awareness of best practice approaches. This was followed with an intensive literature review on the efficacy of industrial ecology as a tool for promoting sustainable industrial development and what legal, policy, technological and institutional frameworks are required for its survival. Additional interviews were held with relevant key informants drawn from Development Agencies, Government Ministries, State Corporations, Academia, Research Institutes, County Leaders and Business Associations on the potential for industrial ecology as a tool for greening Kenya's SEZ and what needs to be done to accelerate its uptake.

In order to ascertain the total number of clusters at the Athi River SEZ, an up to date inventory of all the operational companies in the zone was developed. The firms were then classified on a sector-wise basis and on the basis of integration of activities and collaboration of members for mutual benefit and investigated for waste and by-product exchange. The concept of clustering referred to in this thesis means local concentrations of horizontally or vertically linked companies which specialize in related lines of business together with supporting organizations (Porter, 1990). Four clusters out of the zone's total were selected for detailed investigation. This involved assigning numbers to each of the identified clusters. These numbers were written on small papers, folded and haphazardly mixed in a container before being picked. The identified clusters were benchmarked against a World Business Council for Sustainable Development (WBCSD) standard guidelines on assessment of the Industrial Symbiosis (IS) potential with a view to identifying gaps that need to be addressed if the clusters are to be sustainably grown while fully embracing resource efficiency and industrial symbiosis. In this thesis, a cluster is defined as a territory comprising of a high concentration of small and medium scale enterprises with highly specialized production, generally greatly interdependent in their production cycles and strongly integrated with the local socio-economic environment (Porter, 1990; Klimova et al. 2016).

\section{Data Analysis and Interpretation}

In order to demonstrate the efficacy of industrial ecology as an effective tool for helping to convert the wasteful linear economic development model at the Athi River SEZ into a sustainable and resource efficient circular economic development model, material flow analysis and tracking was undertaken among the evolving symbiotic relationships of the four identified clusters for detailed investigation. The aim was to track, measure, and quantify wastes and by-product material flows within the emerging symbiotic relationships weekly for a period of two months and then use the established waste and by-product generation averages to project annual symbiotic exchanges. In the agro-processing cluster, it was demonstrated that the reuse of the residual seed cake for animal feeds manufacture led to energy savings in production, reduced transportation costs, and avoided emissions. For the garment cluster, the recovery of the garment offcuts for use as boiler fuel and in sofa set manufacture led to avoided climate damaging emissions and creation of 15 decent green jobs. The reuse of tarpaulin plastic off cuts for the manufacture of plastic water tanks and chairs after on-site reprocessing led to the creation of 5 decent green jobs. 


\section{Research Findings}

This study found that the cluster zonation approach was not part of the initial master plan that created the Athi River SEZ since the master plan was developed in the 1980s long before the cluster concept took root globally (Porter, 1990). This means that adoption of the cluster initiative for increased competitiveness of the economic zone has to be treated as a new development project. As a result, the tenant company's readiness to engage in active pooling of sustainability knowledge and know -how was low. It was therefore difficult to establish mutual trust between companies that have for a long time operated independently from each other and are now being persuaded to cooperate and compete at the same time. Participating companies must be assured that their trade secrets will not be misused. A cluster champion will be to help develop joint internal and external communication networks that will aid the coordination of zone wide cluster activities.

Four clusters namely agro-processing, garments, plastics and darts/darts board manufacturing were randomly selected from a total of 11 clusters for in-depth investigation as regards what they were exchanging with respect to the management of their wastes and by-products.

The results reveal a spontaneously emerging cluster network within the economic zone that is largely driven by the prevailing forces of supply and demand; an existing intercompany material flow system that is being hampered by a weak waste recovery and recycling infrastructure; a limited application of the principles of industrial ecology in mitigating the environmental challenges of the economic zone; and a weak governance structure that is incapable of enabling the economic zone to assume low-carbon, resource efficient and climate resilient operational status. For the economic zone to fully adopt low -carbon and resource efficient status, its tenant companies must unanimously shift their production lines from linear to closed loop systems where wastes from one production line become inputs for the other. Doing this will reduce pressure on the use of virg in materials and also lower the carbon footprint of the economic zone by diverting vast amounts of waste from the landfill. In other words, there should be no such a thing as waste within the economic zone - since one industry's waste or by-product should become the raw material for the another production line.

The research project revealed an unregulated evolution of industrial symbiosis (IS) at the zone in four clusters. These comprised use of (i) 240 tons/year of seed cake by-product as raw material for animal feed manufacturing leading to $80 \%$ secondary transport energy savings and $86,427 \mathrm{~kg} \mathrm{CO2e} /$ year of reduced emissions; (ii) 108 tons/year of tarpaulin waste as raw material for making plastic water tanks leading to the creation of five on-site plastic reprocessing green jobs; (iii) 255 tons/year of textile fabric off cuts for making sofa sets and on-site steam generation leading to the creation of fifteen green jobs and $9 \%$ avoided emissions $(1,142 \mathrm{~kg}$ CO2e) and (iv) 204 tons/year of chipboard saw dust waste used as steam boiler fuel replacing fuel oil with $11 \%$ avoided emissions $(4,448 \mathrm{~kg} \mathrm{CO}$ e). Inter-company use of wastes and byproducts as raw material inputs reduced the raw material transport co sts by over $80 \%$ resulting in a lower carbon footprint. Waste reuse diverted the potential solid wastes from the landfill, created new products and jobs, hence contributing to the country's green growth agenda. However, most of the zone's material flows were largely linear due to lack of policy and weak infrastructure for waste recovery and reuse. There was no evidence of genuine partnerships with communities; no strategic co-locating of industries that exchange wastes; no functional infrastructure for IE promotion; no IE enabling policies/incentives; and limited commitment to a resource efficient zone.

The Kenyan Government should work towards strengthening the entrepreneurship ecosystem of incubator businesses within the economic zones. According to the Global Entrepreneurship and Development Institute (GEDI) Global Entrepreneurship Index, 2017, Kenya's strongestarea 
is in process innovation while its weakest area is in start-up skills (GEDI, 2017). In terms of entrepreneurship ecosystem management support to entrepreneurs, Kenya ranks 107 out of 137 countries globally and 11 out of 30 countries in sub-Saharan Africa (GEDI, 2017). The index below for Kenya illustrates weaknesses in a wide range of performance areas that unfortunately are not being adequately addressed at both National and County Government levels. This means addressing issues to do with opportunity perception, acceptance of risk, ability to network, creation of an enabling cultural environment, spotting of potential startup opportunities, capability for technological absorption, human capital skill set development, need to be competitive, ability to embrace product/ process innovation, ensuring accelerated growth, and ability to deal with capital risks (GEDI, 2017).

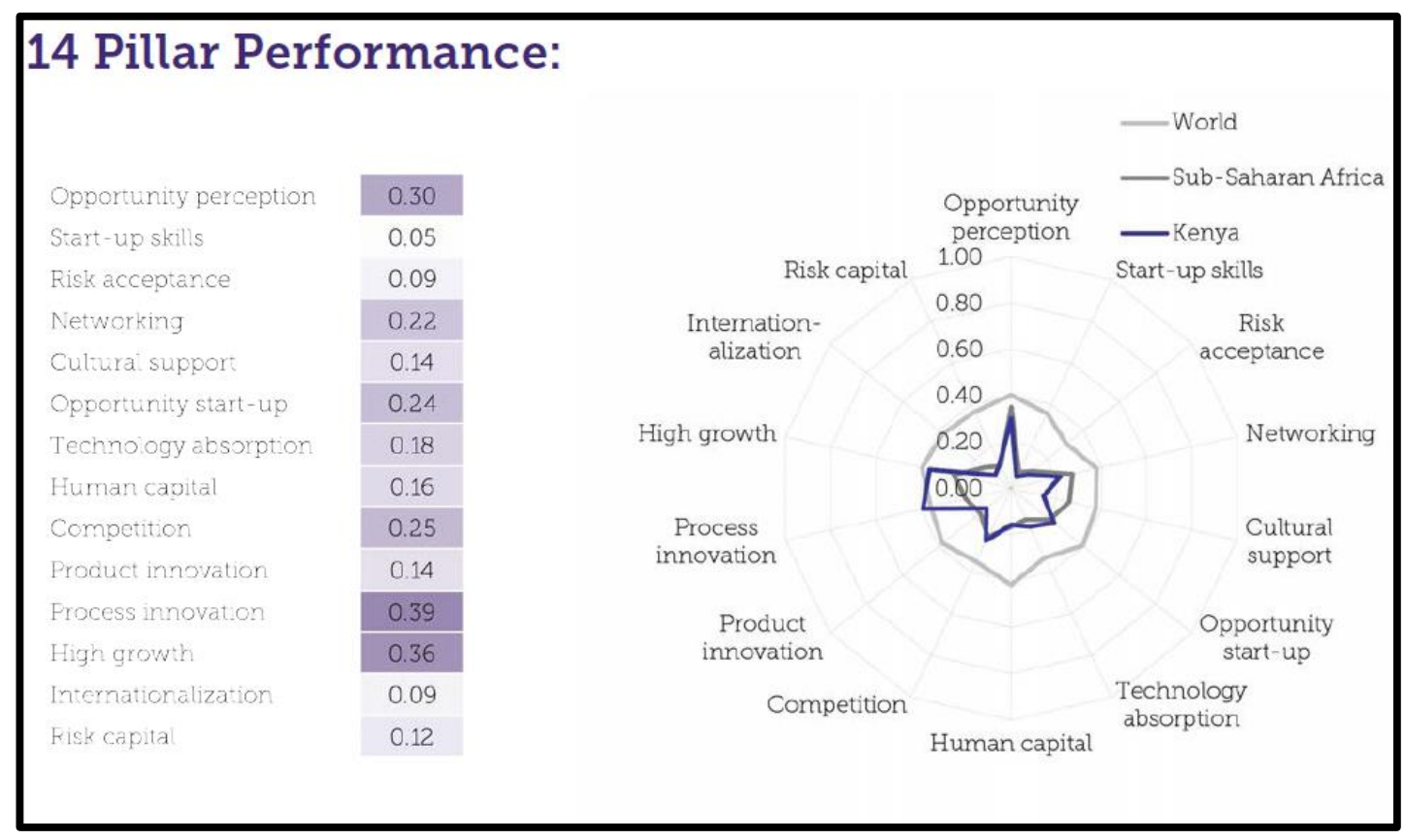

Figure 1

Source: GEDI, 2017 Global Entrepreneurship Index

\section{Conclusion and Recommendations}

The identified clusters at the economic zone were not pre-planned but instead evolved on their own due to the prevailing market forces of supply and demand. Although clusters do provide a powerful framework in which companies organize, work together with the Government and academia in promoting their growth interests, their meaningful growth can only be assured if there is an enabling policy, legal and institutional framew ork. Proper initial planning of the zone will have ensured that those cluster companies that exchange wastes and by-products were located in close proximity to each for purposes of easing the exchange.

Waste and by-product exchange through industrial symbiosis was at its infancy at the economic zone. Detailed investigation of the material flows in the selected clusters revealed that some cluster companies were already exchanging wastes and by-products. However, the industrial symbiosis's much anticipated progress is likely to be slowed down by the zone's weak infrastructure for waste recovery and recycling. Though at infancy, waste and by-product exchange has already helped to create green jobs, lowered GHG emissions, and lowered costs of production. There was no metering and sub-metering of material flows through the production 
lines. This has dampened the full exploitation of the benefits of industrial symbiosis by the economic zone.

The tenant companies of the zone were just beginning to embrace the principles of industrial ecology by deliberately attempting to connect waste and by-product streams into closed loop supply chains. By seeking ways to "close-the-loop" on material cycles, IE extends the useful life time of material resources and reduces the impact of their acquisition on the environment (WBCSD, 2002). On a prioritized basis, the zone companies should fully embraces the principles of resource use efficiency and cleaner production before engaging industrial symbiosis in mitigating its environmental challenges. This will entail awareness raising, training and setting up of demonstrations by the proposed "Green Cell".

It was established that the EPZA as is currently constituted does not have the human and techno-managerial capacity to promote low-carbon, resource efficient and climate resilient growth pathways for companies that reside within the zone. The global trend has shifted to increasing economic zone competitiveness through improved resource use efficiency, cleaner production, and industrial symbiosis. This new development paradigm is meant to decouple economic growth of zones from further increases in greenhouse gas (GHG) emissions and harmful waste generation (UNEP, 2011; World Bank, 2014). Speedy adoption of Industrial Ecology in Kenya will depend on the country's ability to set up demonstrations that show that embracing the concept makes good business and environmental sense as has been successfully done in Europe and Asia. There will also be need for incentives to help accelerate the rate of adoption.

1. The economic zone's industrial clusters were spontaneously evolving. For them to mature and serve the intended purpose of tenant company cooperation towards the common and shared vision of embracing waste and by-product exchange through industrial symbiosis; strengthening of business networking and best practice exchange; engaging team effort in solving waste related environmental challenges, and linking and aligning the different stakeholder interests from a triple helix perspective, there will be need for the establishment of an industrial cluster promotion policy framew ork for our special economic zones (SEZs)/ industrial parks (IPs). The industrialization process of our SEZs/ IPs should therefore be cluster based and that this requirement should be incorporated early during the develo pment of SEZ/ IP Master Plans. The cluster approach to industrialization will enable the country's SEZs/ IPs strengthen their consensus building capabilities on key issues of mutual interest such as industrial symbiosis; enhance company-to-company interaction; and strengthen the University/ Research Institute Industry-Government collaboration in promoting eco-innovation for the much needed green growth.

2. The material flow patterns within the Athi River SEZ were largely linear in the sense that raw materials are mined, value added to produce products that are consumed with a trail of waste at each stage of this supply chain. This waste certainly finds itself to the landfill. There is therefore need to create an enabling policy and institutional framework that will work towards converting the economic zone's current wasteful linear production economic model into a circular economy that seeks to divert wastes from the landfill. Embracing such a circular economy will help reduce pressure on the use of virgin raw materials and also avoid the negative environmental impacts of landfilling wastes. This is why this research is recommending the creation of a "Green Cell" to be housed at the Export Processing Zones Authority (EPZA) and work closely with KIRDI's Green Growth Advisory Centre (GGAC) in advancing the economic zone's green growth agenda based on a circular economy approach. There will also be need to strengthen the zone's waste recovery and recycling infrastructure so that zone companies are enabled to exchange wastes and by-products. Doing this will help create decent green jobs and also conserve the environment. There will be need for an on-line database of wastes and by- 
product generation within the economic zone for purposes of seeking to establish industrial symbiosis synergies.

3. The application of industrial ecology principles for mitigation the environmental challenges of the Athi River SEZ were rather low and in most cases non-existent. As a result, zone based Production Managers were reacting to already generated waste (end-of-pipe approach) as opposed to being pro-active and preventing its generation at source. Consequently, there is need for awareness raising, information dissemination, training and capacity building, and setting up of convincing demonstrations on contemporary tools of environmental management such as resource efficient cleaner production (RECP), the 3Rs, Green Economy, and waste and by-product exchange through industrial symbiosis as a way of seeking to obtain top management buy-in.

4. The Export Processing Zones Authority (EPZA) as is currently constituted did not have the technical and human resource capacity to promote the green growth agenda for all the companies that operate within its licensed economic zones across the country. These shortcomings can be strengthened through triple helix collaborative framework between Universities, Industries, and Government that creates an innovation ecosystem powered by Research, Development and Demonstration (RD\&D).

5. The SEZ Act of 2015, the draft SEZ policy, and the draft SEZ regulations were all inadequate in as far as the incorporation of the elements of sustainability in the management and governance of SEZs. All the three documents did not address the need for Kenyan SEZs to go green and by doing so be in a position of attracting green foreign direct (FDI) investments. Therefore, the country's special economic zone (SEZ) Act, draft SEZ policy, and draft SEZ Regulations, should be reviewed to insert priorities on Resource Use Efficiency, Cleaner Production, the $3 R$ s of reducing, reusing and recycling wastes, and Industrial Symbiosis as the most preferred low-carbon, resource efficient, and socially inclusive development pathway that will enable the country's SEZs to realize increased productivity and competitiveness.

6. The country should develop inclusive green growth development strategies, action plans, and implementation plans for all its SEZs that puts priority on resource use efficiency and cleaner production (RECP), and industrial symbiosis as a way of advancing the green growth agenda through the $3 R$ philosophy of reducing, reusing and recycling.

\section{References}

- Asian Development Bank (ADB). 2012. Policies and Practices for Low -Carbon Green Growth in Asia: ADB-ADBI Study on Climate Change and Green Asia

- Bermejo, R. 2014. Handbook for a Sustainable Economy: Springer Science and Business Media Dordrecht European Commission Decision, C. 2014: 4995 of 22 July 2014: Horizon 2020 - Work Program 2014 - 2015: Climate Action, Environment, Resource Efficiency and Raw Materials;

- European Environment Agency (EEA), 2014. Resource-efficient Green Economy and EU Policies, EEA Report, No. 2/2014;

- Export Processing Zones Program Annual Performance Report, 2013 by the Export Processing Zones Authority (EPZA);

- Global Entrepreneurship and Development Institute (GEDI), 2017. Global Entrepreneurship Index;

- GOK, 2013. National Climate Change Action Plan (NCCAP) 2013 - 2017; Ministry of

- Environment, Water and Natural Resources;

- GIZ, (2015a). Planning of New Industrial Parks and Investment Zones, Indo-Germany Partnership on Sustainable Industrial Development; 
Greening Kenya's Special Economic Zones and Industrial Parks: Achieving their Competitiveness in the face of Resource Scarcity and a Changing Climate Regime

- GOK, 2015. National Green Economy Strategy and Implementation Plan (GESIP) for Kenya;

- Lowe, E.A. 1997. Creating by-product resource exchanges: strategies for eco-industrial parks. Journal of Cleaner Production 5 (1-2): pp. 57 - 65. Crossref

- Lowe, E.A. 2001. Eco-industrial Park Hand Book for Asian Developing Countries, Report to Asia Development Bank;

- Porter, M. E. 1990. The Competitive Advantage of Nations. London, Macmillan. Crossref

- UNIDO, 2015. Economic Zones in the ASEAN: Industrial Parks, Special Economic Zones, Eco-Industrial Parks, Innovation Districts as Strategies for Industrial Competitiveness, UNIDO Country Office in Vietnam, August 2015;

- UNEP, 2011. Towards a Green Economy: Pathways to Sustainable Development and Poverty Eradication - A Synthesis for Policy Makers. www.unep.org/greeneconomy;

- World Business Council for Sustainable Development (WBCSD), 2002. Industrial Ecology in the Cement Industry, Toward a Sustainable Cement Industry, WBCSD Business of Innovation;

- World Bank, 2014. Low-Carbon Zones: A Practitioner's Handbook, Washington, D.C, May 2014; 